\title{
STUDIES WITH SUDAN III IN METABOLISM AND INHERITANCE
}

\author{
OSCAR RIDDLE
}

From the Laboratories of Experimental Therapeutics and Zoölogy, University of Chirago

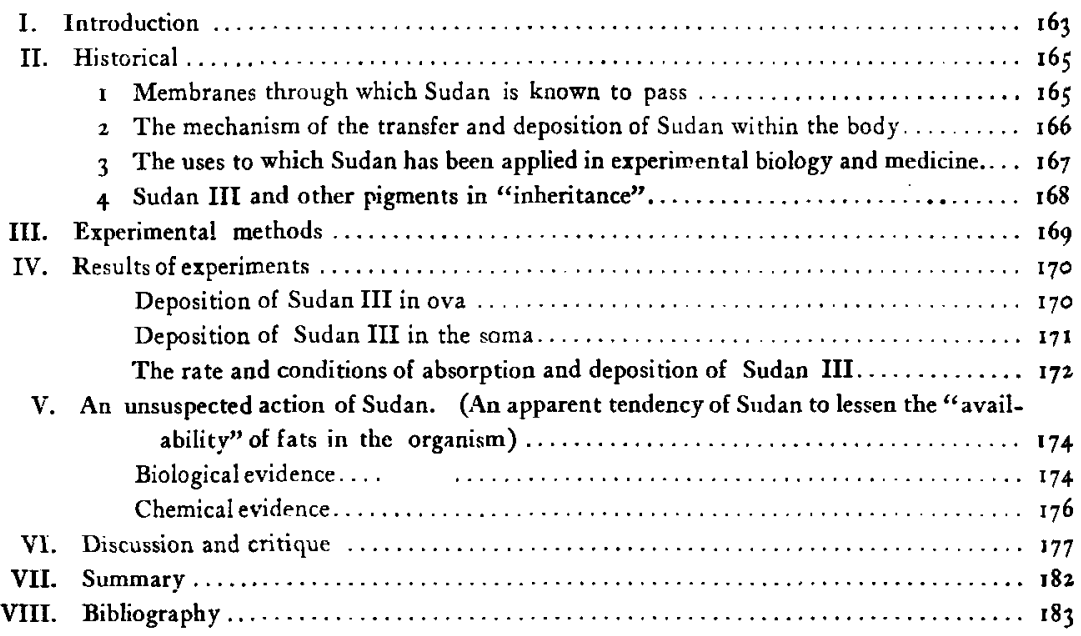

\section{INTRODUCTION}

In a paper presented before the American Society of Zoölogists, December, I907, the writer (07) described and demonstrated, among other things, the deposit of Sudan III in the egg of the domestic fowl. A very brief abstract of this paper was published in Science, June, 1908. All of the data concerning the method of in troducing the color in to the eggs, and the significance of this in metabolism and inheritance, as well as the data concerning an in terpretation of the white and yellow yolk of vertebra te ova, were then written up together. It now seems advisable however, to treat the first two subjects apart from the last since the phenomena 
of inheritance involved in the transmission of this aniline dye have attracted an amount of attention which make a fuller treatment necessary. ${ }^{1}$

It is important that any statement concerning the inheritance of this or another pigment be accompanied by a statement of the facts concerning the behavior of this substance in metabolism. That is to say, if we make statements concerning the passage of a substance through follicular cells and of its deposit, distribution, behavior or development within germ cells and in their derivatives, it is obviously important to keep in view what we know regarding the way this substance passes through other membranes; how it exists, is distributed, beha ves or develops in somatic cells. It is of value to realize how these things happen in any membrane or cell of the body, because it is this same how, or in other words, the mechanism of such successive transformations in the germ, that is the very self of inheritance. Again, if we state our results on inheritance in terms of metabolism we are, in this case at least, less liable to exaggerate the importance of our

\footnotetext{
1 Luring the two years since this paper was prepared and read other workers have undertaken and reported work along similar or related lines; and quite recently, within four months, three papers have appeared which make it seem advisable to divide this paper into two parts, and to publish in full without further delay the part most intimately connected with the present title. One is the more readily persuaded to this division and immediate publication because of a communication which appeared in Science, September, ryog. T.r. Ludwig Sitowski there directs attention to the fact that he had secured the deposit of Sudan III in the eggs of moths, and had published an account of his experiments as early as 1905 , but that his paper has been overlooked until now by the writer and apfarently by others. With pleasure the writer hastens to make acknowledgment of his excellent work. Only the timely appearance of his communication together with the fortunate circumstance of delay in the publication of this article have made it possible to give his work the credit it deserves. It is hoped that Lr. Sitowski wil: realize that the place and title of his publication were such as t') make it not difficult for American workers to overlook.

Sitowski evidently has not seen even the abstract of the writer's paper but only a short notice or review of it which was written by $H$. A. in the Zeitschrift f. d. Ausbau der Entwicklungslehre, Bd. III, Heft 2, 1909.

The writer's report of this work has received notice in several quarters, and in almost every instance he has been credited with the works of others, or to others has ieen attributed work done by him. In these shiftings he usually has fared better than he deserves; but it scems that the results thus far obtained in this field should be brought together in such a way that it may re made plain just what has been done and incidentally who did the work. It is partly for these reasons that the entire literature on Sudan, so far as the writer has been able to find it, is here brought rogether and an outline of the results given.
} 
results; while at the same time we get a close view of the sort of mechanics which is back of this type of "inheritance." We may sta te at once our belief that we are here dealing with a noteworthy, though very simple, form of inheritance, but one which seems by no means sufficient to illuminate hereditary processes in general.

By the use of Sudan the writer has been able to demonstrate some hitherto unrecognized features of fat metabolism, particularly as it occurs in birds. It seems both convenient and helpful to report these results in connection with the present survey of Sudan in metabolism and inheritance.

\section{HISTORICAL}

The historical background of the present studies is furnished by a view of the state and source of our knowledge of the four following topics:

(I) The living membranes through which Sudan will pass, and the points at which it is deposited in the body.

(2) The mechanism of the transfer and deposition of Sudan within the body.

(3) The uses to which Sudan has been put in experimental biology and medicine.

(4) Sudan III, and other pigments, in "inheritance."

In summarizing the data on these topics it has been considered to the advantage of the reader, to include the results of the writer as well as those of other investigators whose findings have been published since the preliminary report of his own work. The summaries, therefore, are believed to be complete to date.

(I) Membranes Through which Sudan is Known to Pass

Intestinal mucosa: birds and mammals, (Daddi, '96).

Intestinal mucosa: human, (Franz and Stejskal, 'o2).

Intestinal mucosa: moths, (Sitowski, '05).

Embryonic intestine: yolk-sac of chick, (S. H. \& S. P. Gage,'o8). Renal epithelium: human, (Franz and Stejskal, 'O2).

Epithelium of egg chamber: moths, (Sitowski, '05). 
Follicular epithelium: birds, reptiles, mammals, (Riddle,'o7 b). Epithelium of mammary glands: rat, (Gage, Stotsenberg, 'o8 b). Thecae of Corpus luteum: rabbits, (Riddle, this paper).

Peritoneum: birds, (Riddle, this paper).

(2) The Mechanism of the Transfer and Deposi ion of Sudan within the Body

Practically all we know concerning the mechanism of the transfer and deposition of Sudan we owe to the feeding experiments and observations of Daddi, to the studies on the solubility of the stain by Pflüger and Nerking, and to the chemical researches of Michaelis.

Daddi ('96) found that when fed to rabbits, guinea-pigs, pigeons and fowls, Sudan passes through the in testinal epithelium, enters the circulation and is deposited in the adipose tissue of the body generally; that it is a specific fat strain, and that in its introduction and deposition in the body it is always associated with fat. Biedermann, ('98) was the next to use Sudan experimentally. He fed the stain to Tenebrio molitor and found that although the in testinal conten ts became colored, the body fat was not colored. ${ }^{2}$ Hofbauer ('oo) made the mistake of supposing that only natural fat and not soap.and fatty acids, was able to carry the dye through the intestinal epithelium, (he used Alkanna which resembles Sudan in its solubilities, and he also refers to Sudan). He thought, therefore, that by use of the stain he could determine in which form the fats are absorbed from the intestine. The paper containing this error, two other papers which repeat it, together with the three or four papers devoted to exposing the error, furnish nearly one-half of the litera ture dealing with Sudan III. Pflüger ('oo) and Friedenthal ('oo) simultaneously pointed out Hofbauer's mistake, showing that under the conditions furnished by the intestine Sudan is soluble not only in fat but in bile, in sodium soap and in glycerine. Frieden thal, however, declared that soaps have no power to dissolve the stain in the absence of free fatty acids. Nerking ('oo) immediately showed that entirely

\footnotetext{
${ }^{2}$ Prof. T. H. Morgan informed the writer that in a fly, Drosophila, he has recently obtained a similar result.
} 
neutral soaps do have the power to dissolve Alkanna, Lackroth and Sudan. It may be pointed out that Sitowski ('O5) repeated Hofbauer's error al though he based no conclusions upon it. Whitehead ('og) without knowing of Hofbauer's work attempted to solve the same problem in a like manner. Mendel ('og) has shown that Whitehead was further mistaken in his observation that after a dog has been fed with Sudan, the lymphatics of his mesentery remain unstained. It may be stated here that there is no difficulty whatever in finding the stain in the lymphatics of fowls, if these be examined two or more hours after being fed the dye.

Michaelis ('or)made very careful chemical studies of Sudan and related compounds. He considers the staining of fat a physical and not a chemical process, and draws the conclusion from his work that the physical properties of a body depend upon its chemical character since the dye molecules, to be soluble in fat, must have a very definite constitution. He concludes, "fat will be stained by those azo-dyes which are 'indifferent' in the sense of possessing no salt-forming groups." Mann ('O2) has given some consideration to the nature of the union of Sudan with fatty compounds, and on the basis of Michaelis' studies, states (p. 310) that "the union between Sudan III and oleic acid is a chemical one depending on the oxidation of the unsaturated fatty compound. Therefore, the action of Sudan III and similar dyes is analogous to that of osmium tetroxide, the only difference being that azo-dyes form additive compounds with the fat without loss of color, while osmium tetroxide, after having formed additive compounds, is readily decomposed owing to the high valency of the osmium." From either view-point, or indeed from any possible viewpoint, it seems certain that the dye is bound to the fatty constituents, cannot loosen from them, and is dragged with them mechanically, so to speak, wherever they may go.

\section{(3) The Uses to which Sudan has been applied in Experimental Biology and Medicine}

As has been noted, Daddi introduced the stain into histological work, used it as an intra-vitam stain, and by its means studied the foci and extent of various fatty degenerations of the liver 
and muscles. The futile attempts of Hofbauer, Sitowski and Whitehead to determine the form in which fats are absorbed from the alimentary tract have also been mentioned. Franz and von Stejskal ('02) made extended studies on the fat metabolism of a chyluric by means of the stain. When stained fat was fed to the patient the colored fat appeared in the urine in four hours and continued always less than twenty-four hours. When, however, stained fat was injected subcutaneously in to the shoulder it did not appear in the urine.

Sitowski with this stain undertook the solution of certain problems of digestion in the ca terpillar of certain moths. He made little progress with these problems, but in the course of his investigations discovered a deposit of the dye in the eggs (primary oöcy tes) of these forms. The writer has used Sudan in a number of studies and for several purposes. He will mention at this point merely its use in determining the time and rate of growth of the eggs (primary oöcy tes) of fowls and turtles; in the study of some special features of fat metabolism; and to gain some information as to the in ter-relation of the soma and germ cells, including transmission and inheritance behavior. Gage has followed the first report of our results with further studies on the behavior and distribution of this dye in the developing fowl, its appearance in the milk, and with negative results, its passage through the placenta.

\section{(4) Sudan III and Other Pigments in Inheritance}

The only recorded cases known to the writer, of the deposit and persistance of foreign or maternal pigments within germ cells, are the following: Schmidt ('9I) found that Alkannacolored fat was taken up by apparently all plant cells; the ovules of these plants are not specifically mentioned as obtaining part of this coloring matter. ${ }^{3}$ Pizon ('or) states (p. I 70 ) that " the first pigment of the larva (Botrvllides) proceeds from the maternal organism by migration." His observations are not conclusive. Sitowski ('05) fed Sudan to caterpillars and obtained the stain within their eggs. He now reports ('og) the presence of the stain

\footnotetext{
${ }^{3}$ Fat colored with Alcannin had been used by Pfeffer (Osmotische Untersuchungen, 1877) to color the fat being injested by Myxomycete plasmodia.
} 
in the somatic structures of larvae hatched from such eggs. The writer ('07) caused birds and turtles to deposit quantities of Sudan within their eggs. S. H. and S. P. Gage ('o8) have hatched Sudan-containing eggs of the fowl and noted the re-distribution of the stain in the somatic tissues. In addition to these cases, however, it should be noted that it is practically certain that the natural coloring matter of the eggs of the salmon proceeds from the muscles of the fish. It is quite certain that the fat which is in these muscles, and in which much if not all of the coloring matter resides, is transferred to the ovary and to the growing eggs. These lipochromes of the muscle fat doubtless remain fixed to the constituent fatty acids, when this fat is broken up in the muscles and is thrown in to the circulation; from the blood or lymph, we believe, the two enter the ovum together, precisely as in the case of Sudan-stained fat.

\section{EXPERIMENTAL METHODS}

Laying hens were fed Sudan III in three ways, viz.: in gelatine capsules, dissolved in egg-yolk, butter or animal fat, or by enclosing small lumps of the stain in pieces of bread (no fat). The results were very similar in all cases. With birds, the method of feeding seems quite immaterial since the stain apparently always meets with enough fats within the alimentary canal to carry considerable quantities of it through the intestinal wall. The dose varies from one-half gram to three milligrams. For most studies, particularly those dealing with problems of metabolism, large doses are to be avoided; from three to twenty milligrams have been found most useful, Many birds were fed the stain at in tervals of thirty-six, forty-eight and seventy-two hours; series of eggs from birds thus fed were ob tained, were hardboiled, sectioned under water with a sharp razor and then examined, these latter operations being done chiefly to learn the rate of growth of the ova. In other cases the birds were killed at such time after feeding as was demanded by the poin ts under investigation.

The stain was in troduced in to the bodies of chicks and rabbits also by injection of its solution in a mixture of oleic acid and alcohol. A widely variable quantity of the solution was injected 
into the peritoneal cavities of these animals (also in to brachial veins of the chick, and ear veins of the rabbit). The method of feeding the stain to turtles will be described with the results of that work.

\section{RESULTS OF THE EXPERIMENTS}

\section{Deposition of Sudan III in Ova}

The eggs of hens fed as described above almost invariably showed marked quantities of the pigment deposited in the yolks. An ovun which had undergone its final and rapid growth in a bird which was being fed at regular intervals of thirty-six, forty-eight or seventy-two hours would show in section a series of evenly-spaced, concentric circles of orange-red, these alternating with other circles of light yellow, the natural ground color of the yolk. The width of any Sudan-colored circle could have been regulated at will at the time of feeding; much stain giving the wide rings of red, and little stain resulting in narrower rings of less intense color. If the birds be killed a few hours after feeding all of the larger ova are found to be deep red on the outside; if, however, the bird be not killed until one or two days have elapsed since the feeding, these ova will have a perfectly normal external appearance, and only an examination of the interior of the eggs will reveal the presence of the stain. This is, of course, a consequence of the rapid growth of these ova.

One successful attempt was made to stain the ova with Sudan injected in to the peritoneal cavity. Four injections of a mixture of alcohol and oleic acid forty per cent each, to which traces of sodium carbonate were added, were given within a period of forty-eight hours. Four eggs were subsequently laid by this bird and were found to contain the dye.

In the case of the turtles the records are as follows: Three very large females of Emydoidea blandingii were heavily fed with Sudan for three weeks during July and August. The stain was put with butter in to capsules of large size and these were pushed with long-slender forceps in to the stomach, while the neck was stretched and the mouth held open with other forceps. All were killed five days after the last feeding. All of the larger ova 
showed the characteristic color of Sudan at their peripheries. The thin, follicular membranes were slightly tinged with red. In January four similar turtles were fed and killed in the same manner. In none of these cases could Sudan be found within the eggs, although some of the follicular membranes seemed very faintly stained.

This different result during the two seasons is of considerable in terest from the standpoint of determining the season in which the eggs of turtles grow. If the eggs had been growing (depositing yolk) in January, they should have taken up the stain. The fact that they failed to do so is evidence that they are not growing in January. The definiteness of this finding is somewhat vitiated however, by the writer's observation (og) that the digestive capacity of these forms is very low in midwinter; and by the further observation that the forms which were fed the Sudan in winter sometimes regurgitated parts of it. It cannot be stated as certain, therefore, that as much Sudan was put in to the blood of the turtles in winter as in summer. (The turtles were kept from summer until January in aquaria containing water at outside temperature. At the beginning of the feeding experiment they were brought in to water at summer temperature, about $20^{\circ}$ ).

The ovaries from rabbits injected (with the same solution as for the birds) once or twice daily for a week, were examined. Only two of these animals survived the in jections long enough to beconsidered seriously. One of them showed no certain traces of the stain anywhere in the ovaries, the other, only in the corpora lu tea. This work on the rabbits was shared by Prof. S. A. Matthews.

\section{Deposition of Sudan III in the Soma}

Fowls hea vily fed on Sudan, for even a day or two, usually show upon examina tion a reddish color in all their adipose tissues, most prominently in subcutaneous and peritoneal fat. This but confirms Daddi. In addition to his findings, however, it was determined that if newly hatched chicks be fed the stain during the growth of the juvenile plumage the fea thers also take up the stain and become distinctly red in color; (the Sudan-containing offal was of ten and completely removed from the brooders and pens to preven $\mathrm{tits}$ be- 
ing mechanically scattered over the outside of the plumage). The claws and bills of the birds likewise become highly colored, but one cannot be perfectly certain that this color is not of external origin. Injection of the stain gave very similar resul ts; in these cases, however, a more diffuse color was obtained, no attempt was made to color the fea thers and no staining of the in testinal wall was noted. These birds laid down colored fat after having been given the stain by injection in to the peritoneal cavity.

After feeding the stain to turtles one finds but traces of Sudan deposited in somatic tissues. This is undoubtedly due to the fact that they store fat extremely slowly, and that their bodies actually contain but little fat. The further fact of the difficulty or slowness of digestion which the writer (09) has found especially to characterize the turtles, may also be important in this connection.

The subcutaneous fat and the intestinal mucosa were the only parts other than the ova and follicular membranes in which the writer found the stain deposited in turtles. No injection of the dye was attempted in these animals.

Rabbits apparently ingest Sudan much more slowly than do fowls. Nevertheless, upon continuous feeding red-colored fat becomes visible in all parts of their bodies, subcutaneous fat everywhere, peritoneal and kidney fat, the intestinal wall and corpora lutea. Daddi noted a similar distribution (except in the corpora lutea) in rabbits and guinea-pigs. A similar distribution of color results from the injection of the stain (except for the mucosa).

\section{The Rate and Conditions of Absorption and Deposition of Sudan III}

Almost no attention has been given by previous writers to the rate at which Sudan is absorbed and desposited. Since this really represents the rate at which fat is absorbed and deposited, it becomes a matter of considerable interest. Similarly, the conditions of its deposition and non-deposition when it is brough $t$ within the blood-stream, have nowhere received consideration, except, of course, that it has been generally noted that it is deposited in fats. The writer is able to report approximately correct data on these points as they were obtained in the study of the fowl only. 
Many birds were killed soon after feeding with Sudan; the time in tervening between feeding and killing ranging from one-half hour to days and months. From the examination of these birds it was learned: (r) That the stain may appear in the mesenteric lymphatics within a period of seventy minutes after feeding; (2) at end of two to three hours after hea vy feeding a perceptible amount of stain is laid down in the rapidly growing ova; (3) the body fat becomes colored much more slowly than the yolk fat; (4) the several regions of body fat are not all colored simultaneously, even the subcutaneous fat of some regions remaining colorless at a time when subcutaneous fat elsewhere is quite red. This last fact seems to indicate that there are differences between these several "storehouses" of fat; that some are centers of a most active commerce, there being in these a con tinuous loading and unloading of wares; whereas there are other storehouses of fat whose portals during normal conditions at least, are quite tightly closed.

In regard to the conditions under which Sudan is, or can be, deposited, we have determined the following facts: (I) Sudan can be deposited only in growing ova. Indeed, for a perceptible a mount of the stain to be taken up the ova must grow more rapidly than do those ova of the fowl which are less than $5 \mathrm{~mm}$. in diameter. (2) Sudan can be deposited with difficulty, and only in small amounts, in a fowl that is not being fed and is thus made to use $i$ ts store of fat instead of being allowed to grow new fat. These results have been verified on so many birds that there is no doubt of their being entirely reliable. It cannot be said that the starved animals did not get the fat in to their circulation because of failure to absorb the stain under the starving conditions, for some of these birds were given the stain by injection, and they too showed just as decidedly the recults sta ted above. One cannot but see in these two results the very strongest evidence that while in the body, Sudan III clings at all times to the fats or their constituent fatty acids, and so goes quite mechanically wherever these particles go; it is indeed, attached to them. (3) There is moreover in lightly-colored fat a marked tendency of the stain to remain in this fat in the living animal and not to leave it for other contiguous fat. This wes shown by the sharpness of the inner edges of the bands of stain in the ova, as well as by one's ability to circulate stain through the 
body of animals not depositing fat, withoutcoloring certain regions of fat. (4) It was found that within the ovum the Sudan is deposited in the germinal disc and in the la tebra in smaller amoun ts than elsewhere. This is undoubtedly to be associated with the lower fat content of these regions of the egg.

\section{AN UNSUSFECTED ACTION OF SUDAN}

An Apparent Tendency of Sudan to Lessen the Availability of $F$ ats in the Organism. Since 1904, when the writer first fed Sudan to chicks, several things have come under his observation which indicate that $S$ udan-stained fat is not as available,-Coes not split up and yield its energy to the organism as readily--as does the unstained fat. If this could be positively established it would be a very important fact, possibly giving some clue as to what "a vailability" of foods rests upon. We might, perhaps, then proceed so to treat certain foods or constitutents of the tissues as to increase or decrease at will their utilization or destruction within the body.

Some special effort has been made to get positive data on this hither to unsuspected action of Sudan. It must be admitted that conclusive da ta have not been obtained; in their absence the writer can only submit the following record of effor ts, - - few observa tions and experimen ts which seem to con tain some bits of evidence:

\section{Biological Evidence}

(I) Young chicks which were given Sudan with their food a te much more than those not fed the stain; they seemed always hungry and did not grow as well as the other birds of the same age and breed. This, of course, may easily have another explanation than the one suggested.

(2) In a certain "starving" experiment it happened that birds three months old were used, five of which had been given three hea vy feedings of Sudan during the two days immedia tely preceding the starving period. These five Sudan-fed birds were all dead before any of the four non-fed ones showed very great signs of weakness. Three of the five dead birds were carefully examined. They showed Sudan in patches of subcutaneous fat, in other patches along the neck, behind the occiput and even distinct traces 
in peritoneal fat. On the other hand, the muscles showed extreme waste. Two of the birds from the other pen were now sacrificed for comparison. They showed hardly a trace of fat. Dipping them in to an eighty per cent alcoholic solution of Sudan failed to reveal more than traces. The muscles, however, were obvioulsy larger and much better preserved than in any of the Sudan-fed birds. Sudan was found to be a non-toxicant as many birds were fed several months and one adult hen was fed the stain almost continously for ten mon ths without visible injurious effect. This fact, together with those mentioned above, lead one to suspect that the presence of the stain in the fat made this fat in these birds less a vailable than if unstained, and that under the new conditions the energy of the proteins (of the muscle, etc.) became more available than that of the fats.

(3) If birds be fed considerable quantities of Sudan while growing a plumage it will be found that the "fault-hars" of the feathers become more pronounced in extent. It has been shown conclusively that any decrease in the nutrition of the fea ther germs produces these effects. Attention has elsewhere (Riddle, ' $07^{a} \mathrm{p}$. I72) been specifically called to this power of Sudan to produce fault-bars or defective areas in feathers and to the fact that this seems to be due to a starving effect produced by the Sudan.

(4) It has also been pointed out by the writer (08, p. I 74) that if young chicks in their downy plumage be "starved" for a time, or fed Sudan in quantities, there is a common result in the two cases, namely, an inhibition of the growth of most of the definitive feathers and a long retention of the downy plumage. This is evidence of the sort we are just now examining, since these Sudan effects so closely parallel "starving" effects. The following case is perhaps less valuable evidence of the same kind.

(5) It has been observed that many laying hens cease to lay eggs after having been fed considerable quantities of the stain. The effect here is again the same as that resulting from a withdrawal of food; it may, however, have other causes as well.

(6) The above and similar observations led to the following experiments. The one here recorded was made after nos. 7 and 8

\footnotetext{
4 Sec Oscar Riddle on the Genesis of Fault-hars in Feathers and the Cause of Alternation of Light and Dark Fundamental Bars. Biol. Bull., vol. 14, pp. 328-37c, 1908.
} 
had failed to sa tisfy. Six plymouth rock hens in good condition, not laying, were isolated for the experiment. Quite at random three of these hens were taken and given food + Sudan capsules for two days; the other three were given food but no Sudan. The birds were then all removed to a pen where they could get no trace of food; only water was given them. The weight of each bird was taken at the beginning and on each third day of the experiment during its fifteen days of duration; the object of all this being to learn which group of birds would lose weight faster. It was thought that those using most fat would lose least weight and vice versa; viz., that energy must be supplied to the birds during life, that if they secure this energy from the fats of their bodies instead of from their protein, they will need to use fewer grams to obtain any desired amount of energy since the energy content of fats is to that of proteins as about 9.3 to 4.I. An important part of the records of the weighings unfortunately has been misplaced and the writer cannot give the exact figures; but the net result showed that each of the Sudan-fed birds had lost, at the end of the period, a higher percentage of its initial weight than had either of the non-fed birds.

\section{Chemical Evidence}

(7) It was thought that if the stained fat were less available to the organism, as seems to be the case, this might be connected with a decreased power of the fat-splitting ferment to split such fat. The following attempt was made to determine this point; lipase was prepared from the castor bean and equal quantities of this was put in to flasks, one set containing oil +Sudan, the other pure oil only. Flasks of the two sets, left on the shaking machine and given time for hydrolysis, were then titrated with $\mathrm{n}_{\text {i }}$ เ $\mathrm{NaOH}$, and compared. It was found, however, that the strong and persistent color of the Sudan so obscured the expression of the indicators that it was quite impossible to determine the neutral point in the Sudan-con taining flasks. The titration method of estimating the rate of hydrolysis of the fat, therefore, had to be given up. An attempt was next made to determine the rate or amount of digestion in the two sets of flasks by measurements of their elec- 
trical conductivities. This proved impracticable because of the extremely low conductivity of the oils. The writer is therefore not prepared to sta te whether the presence of the stain in the molecule of fat has any effect upon the power of lipase to hydrolize that molecule.

(8) It seemed advisable next to learn the effect of the presence of the stain on the rate of the spontaneous oxidation of the fats. By a method described elsewhere ${ }^{5}$ Prof. A. P. Mathews and the writer, in connection with other work, made a few experiments on the rate of oxidation of linseed oil with and without the stain. It was determined that the oxidation proceeds more slowly in the oil + Sudan than in pure oil. Light has, however, such a profound effect upon the rate of oxidation that it is perhaps possible to attribute much or all of the retardation measured in our experiments to the absorption of light rays by the Sudan. The question that has been raised of the lessened a vailability of Sudanstained fats must then be left without conclusive answer, but with such evidence as the preceding statements afford.

\section{DISCUSSION AND CRITIQUE}

The main facts at hand have already been given in a rather long historical statement and in the preceding account of the writer's own results. The specific statements on the several topics of fat metabolism need not be again referred to. The general question of the basis or source of usefulness of Sudan III in such studies as the present may, however, be touched upon here. We can now consider too another most in teresting aspect of our subject, namely, the significance in inheritance of the observed transmission of this aniline dye from soma to germ cell, and its redistribution among the daughter cells of the germ. We treat the former topic first.

In the study of the problems of fat metabolism, what is it that gives value and significance to the use of Sudan III? The answer must be that it is because Sudan sticks to fat or fatty constituents as long as they remain such in the body. Where the

\footnotetext{
- See article by A. P. Mathews, O. Riddle and S. Walker, The Spontaneous Oridation of Some Cel! Constituents, Abstract in Journ. Biol. Chem. vol., 4, p. xx. June, 1908.,
} 
original ${ }^{6}$ stained fat goes, we believe from our experience, the stain will go also; the tell-tale color of the Sudan betraying at once both the presence and the source of the fatty materials in transformation. We are thus enabled to study such aspects of fat metabolism as involve transfer, and re-deposition of fat, etc., which have been open to almost no other means of attack. Indeed, few organic constituents of the body other than the fats, are open to such methods of study even now. The sum of our present information shows quite clearly that the Sudan holds to the constituent fatty acids even when the in tegrity of the fat molecule is lost; this, during its transfer within the body fluids, through practically all of the membranes of the body, and during re-syn thesis, in whatever part of the body this may occur. In all these states and relations the pigment maintains the union; apparently only during the oxidation and final destruction of the fat is the alliance broken. How far the oxidation must proceed before the disunion occurs, the writer is unable to say.

The facts already brought forward concerning the behavior of Sudan in several aspects of fat metabolism furnish some solid ground upon which to base a discussion of the transmission and "inheritance" phenomena involved in the passage of Sudan into the egg and the embryo. We can get a clear vision of this field of fact if we now focus on two points: What are the processes concerned in the en trance of the $\mathrm{d} y \mathrm{e}$ in to the egg, and in its re-distribution in the newly arising cells of the embryo? How do these processes compare and contrast with processes known to be involved in inheritance and developmental phenomena? The answer to these questions should bring in to relief a safe estimate of the significance of the transmission phenomena in question.

The facts absolutely support the view that the passage of the stain through the follicular membrane, which has here been shown, is in no way unlike its passage through the in testinal epithelium or any other membrane. The Sudan, playing here an entirely passive rôle, is taken mechanically to whatever point the fat goes and remains with the fatty acids wherever they again become anchored through resynthesis into fat. The processes involved

\footnotetext{
"This holds true apparently when the fat is lightly stained. Statements made elsewhere furnish the necessary qualifications, and the evidence.
} 
in the re-distribution of the stain and fat in the cells which arise by division of the egg, are not different. Here we must believe that each cell of a dividing pair will carry stain in very close proportion as it carries fat. This is the testimony obtained from all somatic tissues and the writer has shown that the general conditions of this statement are fulfilled in the oöcyte and egg itself, since the germinal disc and the latebra of these stages take least stain (intra vitam) and are known to contain least fat. When in the course of development there arises a variety of body regions, some of which are less favorable for oxidations and therefore more favorable forthe storage of fats, the stain-containing fats may become transferred to these regions of the embryo, precisely as occurs in the somatic tissues of the adult. Localized areas of stained fat thus arise during embryonic life.

If now one compares and con trasts these processes with those known to accompany inheritance, i. e., developmental processes, some interesting features appear. There is, to be sure, transmission of the dye from soma to germ, there is a persistence of that which is transmitted to such an extent as to cause this soma obviously to display the "new character." If in the chick the body fat were used up in egg production, ${ }^{7}$ as was elsewhere noted to occur in the salmon, some of the dye would of necessity again be deposited in the several eggs next formed; these eggs would in turn supply the somatic tissues developing from them. But this must inevitably come to an end in a few generations, the stain, sooner or later, having become diluted to the vanishing point. Again, there is absolutely no new growth of the material forming this "character," nor is there any chemical change either in early or in la te phases of the life cycle. Morphological change does however, accompany each change in the disposition of $\mathrm{fat}$ within the organism, the color-picture thus being a moving one, different in each succeeding stage of development.

These striking contrasts with what we recognize as the basic things in developmental phenomena may well cause many to inquire: Why do we stop at all to consider the phenomena under

\footnotetext{
'I have observed a hen to lay four eggs after the beginning of a "starvation" experiment; the last of those eggs was laid on the twelvth day of starvation and much of the fat of its yolk was undoubtedly derived from the body fat of the bird.
} 
observation, as inheritance phenomena? The reason is that inquiry and reflection seem to attest that this behavior of aniline dye is not an isolated thing in nature but that certain behaviors are known which are universally treated as "hereditary," and which rest upon essentially the same base. There is then, a group of cases which exhibit the simplest known inheritance phenomena, and which may be considered in the light of, and be largely explained by our experience with Sudan.

At the outset we call attention to the simplest analogy: the fact that the en tire fat content of the egg yolk, which in the egg of a fowl aggregates several grams, is without doubt transmitted from the soma to the egg in the same way that Sudan is transmitted. That is to say, the fatty acids, which are re-s $y$ nthesized in to fat within the yolk pass from the soma (i. e., from within the body fluids) through the follicular membrane as these same fatty acids; the fatty acid constitutents of the egg-yolk by no means originating within the egg. This conclusion follows as a logical necessity from our knowledge of fat metabolism elsewhere in the body, as well as from the special findings of Henriques and Hansen (03), who report the recovery of the specific and foreign fats of the food from the egg-yolk of the fowl. Moreover, from the standpoint of our general knowledge of metabolism it is not to be expected that these constitutents of the egg-yolk should reach the latter in any other form. The protein of the egg-yolk, must also be conceived as having entered the egg, or at least to have approached it, in a simpler form than protein, namely, as amino acids, etc.; the reconstruction of these doubtless occur chiefly within the egg itself and in this way give rise to the complex and special proteins of the egg.

These things which occur in the formation of every egg, these "transmissions" of amino and fatty acids from soma to germ, are cited because some biologists have considered the passage of a molecule of dye, (azo-benzene "azo" $\beta$ naphthol) from soma to germ, a thing not at all to be expected. Perhaps this state of thought is but an echo of the thoroughness of our long instruction on the wide gulf supposed to separate germplasm and somatoplasm; on an implied immunity proceeding from follicular walls, and an inviolate incorruptibility thought to preside over 
all that lies within a vitelline membrane. Nevertheless the analogy holds: the mass of fat and protein in the egg of the fowl is transmitted from parent to germ. This fat, moreover, neither immediately disappears nor undergoes equal distribution in the embryo, but like the Sudan it persists and becomes specifically localized.

As an interesting example of such localized persistence the writer cites the toad's egg in which Miss King (08) has pointed out that masses of yolk from the developing egg persist in the new germ cells, and that the yolk masses serve to mark off these germ cells as such. Here occurs a passing over of certain constituents from one germ cell to the next generation of germ cells. Of course it cannot be asserted positively in this case that the identical fat molecules of the first egg were contained in those of the succeeding generation. Miss King merely asserts the continuity and persistence of the morphological picture furnished by aggregates of such molecules. The transmitted fats however, exhibit one more advanced stage of complexity of behavior than does Sudan, due to the new combinations they can enter in to and the readiness with which their molecules can be both built up and torn down in the organism.

A second analogy of the transmission and temporary persistence of Sudan we find in the cases of hereditary immunity, observed hither to chiefly in mammals. In these cases, as is becoming well known, the immunity secured by the fœtus through the placenta or germ may be of longer or shorter duration, of ten covering only a fraction of the span of a single generation. It is from the standpoint of the type of transmission displayed by Sudan that these inherited immunities are to be interpreted.

Sitowski has given the analogy of the passage of parasites (spirochætæ and other protozoa) from the soma in to the reproductive cells; the analogy is not complete, as he has pointed out, since in the case of the parasites we deal with living, active forms which seek out the germ cells. Other differences might well be noted. Bacteria also are known to reach germ cells in a similar way.

Of much more interest and weight is the analogy between the behavior of Sudan and that of the glow substances of the glow-

THE JOURNAL OF EXPERIMENTAL ZOB̈LOGY, VOL. 8, NO. 2. 
worm. In Lampyris and Pyrophorus these substances are to be found in the eggs and in every in tervening stage up to the adult. It is true that in this case the substances, in contrast to the Sudan although not contrasting with the fat, do increase in amount at given points in the cycle. But the general features of the two cases agree so closely that actual kinship of beha vior seems certain.

In conclusion, we may emphasize the fact that the transmission behavior of Sudan is the simplest of a simple class, and one of which we can render mechanical explana tion at practically every point. It shows to us the simplest form of inheritance, if the above analogies be granted. If the entrance of fat in to the egg and its persistence there is as stated; if the hereditary immunities are of similar origin; or if the "glow" susbtances mentioned owe any considerable amount of their persistance to the type of mechanics with which we have been dealing in the case of Sudan, then this latter substance has proved of value in giving a view detailed and clearcut, of the mechanism of some phenomena which have been generally considered inheritance phenomena. The writer does rot forget, however, the striking con trasts which these cases present to the great bulk of developmental phenomena, and which seem to present quite a different magnitude of complexity. He wishes to acknowledge his inability, for the present at least, to state how the simpler cases here considered are to enter very deeply in to a solution of the more complex ones.

It need hardly be pointed out, after our detailed account of the action of Sudan, that these studies furnish no basis whatever for the inheritance of acquired somatic characters.

\section{SUMMARY}

I Sudan III fed to fowls and turtles is deposited in their growing ova.

2 Ova and soma of birds and mammals take up this stain after injection in to the circulation or peritonial cavity.

3 The dye molecule is closely united with the constituents of the fat molecules and does not usually separate from them in the body.

- 4 Evidence is obtained indicating that the fat of certain regions 
(in fowls) may increase actively in amount whilst other regions of fat take up no new molecules of fat whatever.

5 The stained fat may appear in the mesenteric lymphatics as soon as seventy minutes after feeding. Perceptible amounts may be deposited on the periphery of growing ova one or two hours later.

6 The stain is taken up very slowly, or hardly at all by birds which are being starved and thus made to decrease their store of fat.

7 Fat stained with Sudan is apparently less a vailable to the organism than is unstained fat.

8 The stain which is passed through the follicular epithelium in to the egg, i. e., in to the newly arising organism-shows there a selective distribution; least stain being found in those parts of the egg which contain least fat, namely, the germinal disc and la tebra.

9 The significance in inheritance of our experience with Sudan lies: (I) in the fact that here we get-through relatively accurate knowledge of the properties and physiological behavior of this aniline dye-a clear picture of how particles of the food or soma become a part of the germ or new generation; (2) in the emphasis which it lays upon the fact that the normal constituents of the egg have a comparable history; (3) in the seemingly perfect parallel which it offers in explanation of the inheritance of immunity, etc.; (4) and the possible light which this extremely simple form of inheritance may throw upon the mass of developmental and inheritance phenomena which seem to be of a much higher order of complexity.

\section{BIBLIOGRAPHY}

(Sudan)

DADDI, L. '96-Nouvelle mèthode pour colorer la graisse dans les tissus. Archives Ital. de Biol., vol. 26.

Biedermann, W. ' 98 - Beiträge zur vergleichenden Physiologie der Verdauung, I. Pflüger's Archiv, vol. $\mathbf{7 2 .}$

Hofbauer, L. 'oo-Kann Fett unverseift resorbirt werden? Pflüger's Archiv, vol. 8 i.

Prü̈ger, E. 'oo-Ueber die Resorption künstlich gefärbtes Fett. Pflüger's Archiv, vol. 81 .

Friedenthal, H. 'oo-Ueber die Permeabilität der Darmwandung $f$ ür Substanzen von hohem Molekulargewicht. Centralblatt für Physiolgie, vol. 14. 
Nerking, J. 'oo-Ueber das Lösungsvermögen von Seifen für fertösliche Farbstoffe. Pflüger's Archiv, vol. 82.

Michaelis, L. 'oI-Ueber Fettfarbstoffe. Virchows Archiv, vol. 164.

Mann, G. 'o2-Physiological Histology, Oxford.

Franz K. and von Stejskal, K. R. 'o2-Ueber das Wesen der Fuvopäischen Chylurie. Zeitschr. für Heilkunde. (Intern. Med.) vol 23, p. 44I.

Sitowski, L. '05-Spostozenia biologiczne nad molowcami( Biologische Beobachtungen über Motten). (Contribution à la biologie des teignes). Bull. intern. de l'Academie des Sciences de Cracovie.

Ridnle, O. 'o7a-A study of fundamental bars in feathers. Biol. Bull. vol. I2.

'o $7 \mathrm{~b}$-The rate of growth of the egg-yolk of the chick, and the significance of white and yellow yolk in the ova of vertebrates. Paper before the Amer. Soc. of Zoöl., Chicago, Dec., Igo7. Abstract. Science, n.s., vol. 27, p. 945, 1908 .

'o8-The cause of the production of down and other down-like structures in the plumages of birds. Biol. Bull., vol. 14, no. 3, 163 .

GaGe, S. H. AND S. P. 'o8a-Sudan III deposited in the egg and transmitted to the chick. Science, n. s., vol. 28, p. 494.

' $08 \mathrm{~b}-$ Coloration of the milk in lactating animals and staining of the growing adipose tissue in the suckling young. Paper before the Amer. Soc. of Anat., Balto., Dec., 'o8. Abstract. Anat. Record, vol. 3, no. 4, p. 203 , 1909 .

Whitehead, R.H. 'o9-A note on the absorption of fat. Amer. Jour. of Physiol., vol. 24 , no. 2.

Mendel, L. B. 'og-The absorption of fats stained with Sudan III. Amer. Jour. of Physiol., vol. 4, no. 5 .

Sirowski, L. 'o9-On the inheritance of aniline dye. Science, n. s. vol. zo, Sept.3, p. 308 .

\section{(General)}

Schmidt, R. H. '9i--Ueber die Aufnahme und Verbreitung von Oelen durch Pflanzen. Flora, vol. I, 74, New Ser. 49.

Przon, A. 'oI-Sur la pigmentation des Tuniciers et la mobilité de leurs granules pigmentaires. Comptes Rendus, Ac. Sc. vol 132, p. 170.

Henriques, V. and Hansen, C. '03-Über den Uebergang des Nahrungsfettes in das Hühnerei und ueber die Lettsäure des Lecithins. Skandinav. Archiv. Physiologie, vol. 14, nะ. 6.

King, H. D. 'o8-The oögenesis of Bufo lentiginosus. Jour. of Morphology, vol. 19 , no. 2.

RIDDLE, O. 'o9-The rate of digestion in cold-blooded vertebrates: the influence of season and temperature. Amer. Jour. Physiol., vol. 24, no. 5. 